\title{
Venous Thromboembolism Prophylaxis After TKA: Aspirin, Warfarin, Enoxaparin, or Factor Xa Inhibitors?
}

\author{
Abiram Bala MD, James I. Huddleston III MD, Stuart B. Goodman MD, PhD, \\ William J. Maloney MD, Derek F. Amanatullah MD, PhD
}

Received: 6 December 2016/Accepted: 24 May 2017/Published online: 31 May 2017

(C) The Association of Bone and Joint Surgeons (B) 2017

\begin{abstract}
Background There is considerable debate regarding the ideal agent for venous thromboembolism (VTE) prophylaxis after TKA. Numerous studies and meta-analyses have yet to provide a clear answer and often omit one or more of the commonly used agents such as aspirin, warfarin, enoxaparin, and factor Xa inhibitors.

Questions/Purposes Using a large database analysis, we asked: (1) What are the differences in VTE incidence in primary TKA after administration of aspirin, warfarin, enoxaparin, or factor Xa inhibitors? (2) What are the differences in bleeding risk among these four agents? (3) How has use of these agents changed with time?
\end{abstract}

Each author certifies that he or she has no commercial associations (eg, consultancies, stock ownership, equity interest, patent/licensing arrangements, etc) that might pose a conflict of interest in connection with the submitted article.

All ICMJE Conflict of Interest Forms for authors and Clinical Orthopaedics and Related Research ${ }^{\circledR}$ editors and board members are on file with the publication and can be viewed on request.

Clinical Orthopaedics and Related Research ${ }^{\mathbb{R}}$ neither advocates nor endorses the use of any treatment, drug, or device. Readers are encouraged to always seek additional information, including FDAapproval status, of any drug or device prior to clinical use. Each author certifies that his or her institution has approved the human protocol for this investigation and that all investigations were conducted in conformity with ethical principles of research.

Electronic supplementary material The online version of this article (doi:10.1007/s11999-017-5394-6) contains supplementary material, which is available to authorized users.

A. Bala, J. I. Huddleston III S. B. Goodman, W. J. Maloney, D. F. Amanatullah $(\bowtie)$

Department of Orthopaedic Surgery, Stanford Hospital and

Clinics, 450 Broadway Street, Redwood City, CA 94063-6342,

USA

e-mail: dfa@stanford.edu; derek.amanatullah@gmail.com
Methods We queried a combined Humana and Medicare database between 2007 and Quarter 1 of 2016, and identified all primary TKAs performed using ICD-9 and Current Procedural Terminology codes. All patients who had any form of antiplatelet or anticoagulation prescribed within 1 year before TKA were excluded from our study cohort. We then identified patients who had either aspirin, warfarin, enoxaparin, or factor Xa inhibitors prescribed within 2 weeks of primary TKA. Each cohort was matched by age and sex. Elixhauser comorbidities and Charlson Comorbidity Index for each group were calculated. We identified 1016 patients with aspirin, and age- and sexmatched 6096 patients with enoxaparin, 6096 patients with warfarin, and 5080 patients with factor Xa inhibitors. Using ICD-9 codes, with the understanding that patients at greater risk may have had more-attentive surveillance, the incidence of postoperative deep venous thrombosis (DVT), pulmonary embolism (PE), bleeding-related complications (bleeding requiring surgical intervention, hemorrhage, hematoma, hemarthrosis), postoperative anemia, and transfusion were identified at 2 weeks, 30 days, 6 weeks, and 90 days postoperatively. A four-way chi-squared test was used to determine statistical significance. Utilization was calculated using compound annual growth rate.

Results There was a difference in the incidence of DVT at 90 days $(\mathrm{p}<0.01)$. Factor Xa inhibitors $(2.9 \%)$ had the lowest incidence of DVT followed by aspirin (3.0\%) and enoxaparin $(3.5 \%)$, and warfarin $(4.8 \%)$. There was a difference in the incidence of PE at 90 days $(p<0.01)$. Factor Xa inhibitors $(0.9 \%)$ had the lowest incidence of PE followed by enoxaparin $(1.1 \%)$, aspirin $(1.2 \%)$, and warfarin $(1.6 \%)$. There was a difference in the incidence of postoperative anemia at 90 days $(\mathrm{p}<0.01)$. Aspirin $(19 \%)$ had the lowest incidence of postoperative anemia followed by warfarin (22\%), enoxaparin (23\%), and factor Xa inhibitors 
$(23 \%)$. There was a difference in the incidence of a blood transfusion at 90 days $(\mathrm{p}<0.01)$. Aspirin $(7 \%)$ had the lowest incidence of a blood transfusion followed by factor Xa inhibitors (9\%), warfarin (12\%), and enoxaparin $(13 \%)$. There were no differences in bleeding-related complications ( $p=0.81$ ) between the groups. Aspirin use increased at a compound annual growth rate of $30 \%$, enoxaparin at $3 \%$, and factor Xa inhibitors at $43 \%$, while warfarin use decreased at a compound annual growth rate of $-3 \%$.

Conclusions Factor Xa inhibitors had the highest growth in utilization during our study period, followed by aspirin, when compared with enoxaparin and warfarin. When selected for the right patient, factor $\mathrm{Xa}$ inhibitors provided improved VTE prophylaxis compared with enoxaparin and warfarin, with a lower rate of blood transfusion. Aspirin provided comparable VTE prophylaxis compared with factor Xa inhibitors with improved VTE prophylaxis compared with enoxaparin and warfarin with the lowest risk of bleeding.

Level of Evidence Level III, therapeutic study.

\section{Introduction}

Venous thromboembolic events (VTEs), including deep venous thrombosis (DVT) and pulmonary embolism (PE), are well-known and well-studied complications after TKA. While VTE incidence has decreased with time, in part owing to routine chemical and mechanical prophylaxis, VTE still remains a challenge and potential major risk during the perioperative period $[13,17]$.

There is considerable debate regarding the preferred thromboprophylactic agent during primary TKA, much of which stems from limitations in studies [4, 25, 36]. For example, while the American Academy of Orthopaedic Surgeons [2] and the American College of Chest Physicians [13] recommend the use of thromboprophylaxis during the perioperative period, despite analysis of many studies, there currently is no consensus regarding the preferred therapeutic agent, especially when considering the balance between VTE prevention and potential bleeding complications [14, 26, 36]. Novel anticoagulants such as factor Xa inhibitors have further confused the discussion regarding the preferred treatment after primary TKA $[28,32]$.

Although all show efficacy after primary TKA, each agent often is compared in isolation with one or another making generalization difficult or leaving one comparison out and creating confusion [10, 15, 16, 31]. As VTE is an uncommon event, it is difficult to acquire sufficient statistical power to discern differences between agents, and as a result the myriad of meta-analyses comparing outcomes continue to reinforce the inadequacy of the retrospective and prospective studies in the area of thromboprophylaxis $[3,5,15,40]$. Numerous studies are further limited by high variability of study protocols, patient volume, outcome measures, and clinical practice [7, 16, 22, 24, 41]. No study to date, to our knowledge, has directly compared aspirin, enoxaparin, warfarin, and factor Xa inhibitors for thromboprophylaxis after TKA because they lacked the power to perform such a comparison.

Given the above, we used a large national database to answer the following questions in patients undergoing primary TKA: (1) Are there differences in VTE incidence between clinical use of aspirin, enoxaparin, warfarin, and factor Xa inhibitors? (2) Between these four agents, what are the differences in bleeding risks, collectively defined as postoperative anemia, transfusion rate, or bleeding-related complications (bleeding requiring surgical intervention, hemorrhage, hematoma, hemarthrosis)? (3) How has use of these four agents changed during the 2007 to 2015 study period?

\section{Methods}

The study used completely deidentified data and was exempt from institutional review board approval. We queried a combined Humana and Medicare database containing records for more than 16 million patients from 2007 to Quarter 1 of 2016 using PearlDiver (PearlDiver Technologies, Colorado Springs, CO, USA). Current Procedural Terminology code 27447 and ICD-9 procedural code 81.54 were used to identify all primary TKAs of interest. To ensure appropriate followup, we only selected TKAs performed between 2007 and Quarter 4 of 2015. This approach guaranteed 90 days of followup for any queried TKA for any postoperative complication appearing on a patient record into and through Quarter 1 of 2016.

The PearlDiver software allows for capture of patients' drug prescription billings on the date the prescription is filled. The database query language allows for identification of patients who have prescriptions filled in a userspecified amount of time before or after a procedural code, in this case TKA. Using this, we first identified all possible anticoagulant and antiplatelet agents found in the database: enoxaparin, warfarin, heparin, factor Xa inhibitors (apixaban, rivaroxaban, fondaparinux), aspirin, dabigatran, clopidogrel, prasugrel, ticagrelor, ticlopidine, cilostazol, dipyridamole, and persantine. We then excluded any patient from our study group who had a prescription for the above medications filled within 1 year before their TKA. Next, we identified our four study groups of interest by searching for patients who had the following thromboprophylactic agents prescribed either during the admission for TKA or within 14 days of discharge: aspirin, enoxaparin, 
warfarin, and factor Xa inhibitors. The factor Xa inhibitors (apixaban, rivaroxaban, fondaparinux) were grouped in a single cohort.

Only patients who had one TKA during the study period were included to allow for accurate tracking of prescriptions and complications, as database software is limited in tracking two starting times. Using a stepwise matching algorithm, we matched all four of our study cohorts by age and sex. The matching process used in this study selects a random sample from an initial larger group of patients, for example, all patients who had warfarin prescribed after TKA, to fit the desired age and sex proportions that match those of the smallest study cohort.

To answer the question of VTE risk, defined in this study as DVT and PE, incidences were queried with the respective ICD-9 diagnosis codes at 2 weeks, 30 days, 6 weeks, and 90 days. The "first instance" command in the language was used when searching these complications, allowing us to identify only the first time any VTE code appeared in a patient's record to prevent any preexisting VTE or bleeding diagnoses from confounding the postoperative outcomes.

To answer the question of bleeding risk, the following three outcomes were searched: postoperative anemia, bleeding-related complications, and transfusion rate. Anemia was defined as the specific diagnosis of acute posthemorrhagic anemia or acute postoperative anemia as identifiable by ICD9 codes. Other sources of anemia were not included. Bleeding-related complications included hemorrhage, hematoma, hemarthrosis, or bleeding requiring surgical intervention [20]. Transfusion was defined as all autologous and allogeneic blood transfusions. Using the "first instance" command, the incidences were queried at the same times as VTE.

To answer the question how prescribing patterns of these agents have changed, the use of each agent was broken down by year. Comparison of yearly increase in utilization rates was made by calculating the compound annual growth rate for each agent.

The list of codes used in this study is available in an online appendix (Appendix 1. Supplemental material is available with the online version of $C O R R^{\circledR}$ ). Comorbidities were compared using a standardized list of Elixhauser comorbidities and the Charlson Comorbidity Index [12, 19].

We identified a total of 1016 patients who had aspirin thromboprophylaxis alone, and were able to match 6096 patients with enoxaparin, 6096 patients with warfarin, and 5080 patients with all factor Xa inhibitors combined by age and sex for a total study size of 18,288 patients (Table 1). With the use of the matching system, there were no differences in age and sex proportions in our study population. The median Charlson Comorbidity Indices, a measure of 10-year survival, were identical for the aspirin $(1$; range, 0 $25)$, enoxaparin ( 1 ; range, $0-50)$, and warfarin ( 1 ; range, 0 48) groups, but slightly elevated for the factor Xa inhibitor group (2; range, 0-60). We evaluated the Elixhauser comorbidity profile for each group (Table 2). Between the aspirin, enoxaparin, and warfarin groups there were differences in individual comorbidities despite equivalence in the Charlson Comorbidity Index. Between the four groups there were differences in 21 of 31 studied comorbidities, with no differences in five of 31 . Five of the comorbidities could not be compared owing to insufficient numbers.

To maintain Health Insurance Portability and Accountability Act (HIPAA) compliance and ensure patient confidentiality, all queries that returned a value between one and 10 patients were given a "null" output. In these instances, the incidence of the complication was determined as less than or equal to the maximum possible value (10 per cohort size). Incidence was calculated for all times. We

Table 1. Matched cohort demographics

\begin{tabular}{|c|c|c|c|c|c|}
\hline Cohort & Aspirin & Enoxaparin & Warfarin & Factor Xa inhibitors & $\mathrm{p}$ value \\
\hline \multicolumn{6}{|l|}{ Age (years) } \\
\hline $45-49$ & $42(4 \%)$ & $252(4 \%)$ & $252(4 \%)$ & $210(4 \%)$ & 1.00 \\
\hline $50-54$ & $96(9 \%)$ & $576(9 \%)$ & $576(9 \%)$ & $480(9 \%)$ & 1.00 \\
\hline $55-59$ & $152(15 \%)$ & $912(15 \%)$ & $912(15 \%)$ & $760(15 \%)$ & 1.00 \\
\hline $60-64$ & $213(21 \%)$ & $1278(21 \%)$ & $1278(21 \%)$ & $1065(21 \%)$ & 1.00 \\
\hline $65-69$ & $234(23 \%)$ & $1404(23 \%)$ & $1404(23 \%)$ & $1170(23 \%)$ & 1.00 \\
\hline $70-74$ & $156(15 \%)$ & $936(15 \%)$ & $936(15 \%)$ & $780(15 \%)$ & 1.00 \\
\hline $75-79$ & $95(9 \%)$ & $570(9 \%)$ & $570(9 \%)$ & $475(9 \%)$ & 1.00 \\
\hline $80-84$ & $28(3 \%)$ & $168(3 \%)$ & $168(3 \%)$ & $140(3 \%)$ & 1.00 \\
\hline \multicolumn{6}{|l|}{ Gender } \\
\hline Female & $645(53 \%)$ & $3870(63 \%)$ & $3870(63 \%)$ & $3225(63 \%)$ & 1.00 \\
\hline Male & $371(37 \%)$ & $2226(37 \%)$ & $2226(37 \%)$ & $1855(37 \%)$ & 1.00 \\
\hline Total cohort & 1016 & 6096 & 6096 & 5080 & \\
\hline
\end{tabular}


Table 2. Comorbidities of study cohorts

\begin{tabular}{|c|c|c|c|c|c|}
\hline Comorbidity & Aspirin & Enoxaparin & Warfarin & Factor Xa inhibitors & $\mathrm{p}$ value \\
\hline Congestive heart failure & $30(3 \%)$ & $336(6 \%)$ & $297(5 \%)$ & $300(6 \%)$ & $<0.01$ \\
\hline Valvular disease & $90(9 \%)$ & $698(11 \%)$ & $582(10 \%)$ & $638(13 \%$ & $<0.01$ \\
\hline Pulmonary circulation disorders & $15(1 \%)$ & $127(2 \%)$ & $149(2 \%)$ & $139(3 \%)$ & 0.03 \\
\hline Peripheral vascular disease & $107(11 \%)$ & $785(13 \%)$ & $619(10 \%)$ & $712(14 \%)$ & $<0.01$ \\
\hline Hypertension, uncomplicated & $604(59 \%)$ & $3887(64 \%)$ & $3798(62 \%)$ & $3302(65 \%)$ & $<0.01$ \\
\hline Hypertension, complicated & $95(9 \%)$ & $789(13 \%)$ & $647(11 \%)$ & $719(14 \%)$ & $<0.01$ \\
\hline Hypertension, both & $607(60 \%)$ & $3915(64 \%)$ & $3817(63 \%)$ & $3317(65 \%)$ & $<0.01$ \\
\hline Paralysis & $\leq 10(\leq 1 \%)$ & $44(1 \%)$ & $40(1 \%)$ & $44(1 \%)$ & N/A \\
\hline Other neurologic disorders & $76(7 \%)$ & $485(8 \%)$ & $469(8 \%)$ & $479(9 \%)$ & $<0.01$ \\
\hline Chronic pulmonary disease & $171(17 \%)$ & $1285(21 \%)$ & $1252(21 \%)$ & $1239(24 \%)$ & $<0.01$ \\
\hline Diabetes, uncomplicated & $219(22 \%)$ & $1588(26 \%)$ & $1524(25 \%)$ & $1404(28 \%)$ & $<0.01$ \\
\hline Diabetes, complicated & $73(7 \%)$ & $551(9 \%)$ & $491(8 \%)$ & $560(11 \%)$ & $<0.01$ \\
\hline Hypothyroidism & $184(18 \%)$ & $1159(19 \%)$ & $1128(19 \%)$ & $1080(21 \%)$ & $<0.01$ \\
\hline Renal failure & $56(6 \%)$ & $440(7 \%)$ & $346(6 \%)$ & $418(8 \%)$ & $<0.01$ \\
\hline Liver disease & $41(4 \%)$ & $270(4 \%)$ & $285(5 \%)$ & $263(5 \%)$ & 0.20 \\
\hline Chronic peptic ulcer disease & $\leq 10(\leq 1 \%)$ & $16(<1 \%)$ & $\leq 10(\leq 1 \%)$ & $13(<1 \%)$ & N/A \\
\hline HIV/AIDS & $0(0 \%)$ & $\leq 10(\leq 1 \%)$ & $\leq 10(\leq 1 \%)$ & $<10(<1 \%)$ & N/A \\
\hline Lymphoma & $\leq 10(\leq 1 \%)$ & $49(1 \%)$ & $41(1 \%)$ & $46(1 \%)$ & N/A \\
\hline Metastatic cancer & $11(1 \%)$ & $48(1 \%)$ & $39(1 \%)$ & $40(1 \%)$ & 0.44 \\
\hline Solid tumor without metastasis & $78(8 \%)$ & $444(7 \%)$ & $438(7 \%)$ & $423(8 \%)$ & 0.10 \\
\hline $\begin{array}{l}\text { Rheumatoid arthritis or collagen } \\
\text { vascular disease }\end{array}$ & $95(9 \%)$ & $723(12 \%)$ & $623(10 \%)$ & $704(14 \%)$ & $<0.01$ \\
\hline Coagulation deficiency & $27(3 \%)$ & $136(2 \%)$ & $156(3 \%)$ & $151(3 \%)$ & 0.10 \\
\hline Obesity & $232(23 \%)$ & $1371(22 \%)$ & $1288(21 \%)$ & $1512(30 \%)$ & $<0.01$ \\
\hline Weight loss & $28(3 \%)$ & $187(3 \%)$ & $165(3 \%)$ & $210(4 \%)$ & $<0.01$ \\
\hline Fluid and electrolyte disorders & $92(9 \%)$ & $697(11 \%)$ & $632(10 \%)$ & $702(14 \%)$ & $<0.01$ \\
\hline Blood loss anemia & $\leq 10(\leq 1 \%)$ & $74(1 \%)$ & $70(1 \%)$ & $66(1 \%)$ & N/A \\
\hline Deficiency anemias & $151(15 \%)$ & $1017(17 \%)$ & $893(15 \%)$ & $933(18 \%)$ & $<0.01$ \\
\hline Alcohol abuse & $20(2 \%)$ & $100(2 \%)$ & $84(1 \%)$ & $85(2 \%)$ & 0.39 \\
\hline Drug abuse & $27(3 \%)$ & $232(4 \%)$ & $166(3 \%)$ & $240(5 \%)$ & $<0.01$ \\
\hline Psychoses & $62(6 \%)$ & $600(10 \%)$ & $493(8 \%)$ & $604(12 \%)$ & $<0.01$ \\
\hline Depression & $139(14 \%)$ & $1061(17 \%)$ & $998(16 \%)$ & $1069(21 \%)$ & $<0.01$ \\
\hline
\end{tabular}

$\mathrm{N} / \mathrm{A}=$ not available

compared all four groups simultaneously via a four-way chisquared test. Significance was set at an alpha less than 0.05 . At the current incidence of events on chemical prophylaxis after TKA, we were powered greater than $80 \%$ to detect a $1.7 \%$ increase in the incidence of DVT, $1.0 \%$ increase in the incidence of PE, $1.2 \%$ increase in the incidence of bleedingrelated complications, $3.5 \%$ increase in the incidence of anemia, and $2.4 \%$ increase in the incidence of transfusion.

\section{Results}

Factor Xa inhibitors had the lowest incidence of DVT and $\mathrm{PE}$ at 90 days. There was a difference in the incidence of
DVT at all times $(\mathrm{p}<0.01)$ (Table 3). At 2 weeks, aspirin $(1.8 \%)$ had the lowest incidence of DVT followed by factor $\mathrm{Xa}$ inhibitors $(2.0 \%)$, enoxaparin $(2.1 \%)$, and warfarin (3.3\%). By 30 days, aspirin (2.2\%) still had the lowest incidence of DVT followed by factor Xa inhibitors $(2.4 \%)$, enoxaparin $(2.7 \%)$, and warfarin $(4.2 \%)$. By 6 weeks, aspirin $(2.5 \%)$ and factor Xa inhibitors $(2.5 \%)$ shared the lowest incidence of DVT followed by enoxaparin $(3.1 \%)$ and warfarin (4.4\%). By 90 days, the factor Xa inhibitors (2.9\%) had the lowest incidence of DVT followed by aspirin (3.0\%), enoxaparin (3.5\%), and warfarin $(4.8 \%)$. Given the HIPAA limitations of the database, we could not accurately find the incidence of PE for aspirin until 90 days (Table 3). There was a difference in the incidence of PE at 
Table 3. Venous thromboembolic events

\begin{tabular}{|c|c|c|c|c|}
\hline Event & 2 Weeks & 30 Days & 6 Weeks & 90 Days \\
\hline \multicolumn{5}{|l|}{ Deep venous thrombosis } \\
\hline Aspirin & $18(1.8 \%)$ & $22(2.2 \%)$ & $25(2.5 \%)$ & $30(3.0 \%)$ \\
\hline Enoxaparin & $128(2.1 \%)$ & $166(2.7 \%)$ & $189(3.1 \%)$ & $216(3.5 \%)$ \\
\hline Warfarin & $203(3.3 \%)$ & $255(4.2 \%)$ & $267(4.4 \%)$ & $294(4.8 \%)$ \\
\hline Factor Xa inhibitors & $102(2.0 \%)$ & $122(2.4 \%)$ & $128(2.5 \%)$ & $149(2.9 \%)$ \\
\hline $\mathrm{p}$ value & $<0.01$ & $<0.01$ & $<0.01$ & $<0.01$ \\
\hline \multicolumn{5}{|l|}{ Pulmonary embolism } \\
\hline Aspirin & $<10(<1.0 \%)$ & $<10(<1.0 \%)$ & $<10(<1.0 \%)$ & $12(1.2 \%)$ \\
\hline Enoxaparin & $48(0.8 \%)$ & $56(0.9 \%)$ & $61(1.0 \%)$ & $69(1.1 \%)$ \\
\hline Warfarin & $86(1.4 \%)$ & $92(1.5 \%)$ & $92(1.5 \%)$ & $99(1.6 \%)$ \\
\hline Factor Xa inhibitors & $33(0.7 \%)$ & $40(0.8 \%)$ & $40(0.8 \%)$ & $45(0.9 \%)$ \\
\hline $\mathrm{p}$ value & N/A & N/A & N/A & $<0.01$ \\
\hline
\end{tabular}

N/A = not available; to maintain Health Insurance Portability and Accountability Act compliance, all queries that return a value between one and 10 patients has a "null" output. In these instances, the incidence of the complication was determined as less than or equal to the maximum possible value (10 per cohort size)

Table 4. Risk of bleeding

\begin{tabular}{|c|c|c|c|c|}
\hline Variable & 2 Weeks & 30 Days & 6 Weeks & 90 Days \\
\hline \multicolumn{5}{|l|}{ Anemia } \\
\hline Aspirin & $188(19 \%)$ & $189(19 \%)$ & $189(19 \%)$ & $192(19 \%)$ \\
\hline Enoxaparin & $1343(22 \%)$ & $1348(22 \%)$ & $1356(22 \%)$ & $1378(23 \%)$ \\
\hline Warfarin & $1270(21 \%)$ & $1283(21 \%)$ & $1293(21 \%)$ & $1318(22 \%)$ \\
\hline Factor Xa inhibitors & $1153(23 \%)$ & $1161(23 \%)$ & $1166(23 \%)$ & $1181(23 \%)$ \\
\hline $\mathrm{p}$ value & $<0.01$ & $<0.01$ & $<0.01$ & $<0.01$ \\
\hline \multicolumn{5}{|l|}{ Transfusion } \\
\hline Aspirin & $68(7 \%)$ & $68(7 \%)$ & $69(7 \%)$ & $71(7 \%)$ \\
\hline Enoxaparin & $766(13 \%)$ & $768(13 \%)$ & $773(13 \%)$ & $786(13 \%)$ \\
\hline Warfarin & $699(12 \%)$ & $708(12 \%)$ & $715(12 \%)$ & $724(12 \%)$ \\
\hline Factor Xa inhibitors & $437(9 \%)$ & $443(9 \%)$ & $444(9 \%)$ & $454(9 \%)$ \\
\hline $\mathrm{p}$ value & $<0.01$ & $<0.01$ & $<0.01$ & $<0.01$ \\
\hline \multicolumn{5}{|l|}{ Bleeding complication } \\
\hline Aspirin & $<10(<1.0 \%)$ & $<10(<1.0 \%)$ & $<10(<1.0 \%)$ & $12(1.2 \%)$ \\
\hline Enoxaparin & $67(1.1 \%)$ & $76(1.2 \%)$ & $78(1.3 \%)$ & $93(1.5 \%)$ \\
\hline Warfarin & $65(1.1 \%)$ & $80(1.3 \%)$ & $85(1.4 \%)$ & $90(1.5 \%)$ \\
\hline Factor Xa inhibitors & $46(0.9 \%)$ & $63(1.2 \%)$ & $66(1.3 \%)$ & $70(1.4 \%)$ \\
\hline $\mathrm{p}$ value & N/A & N/A & N/A & 0.81 \\
\hline
\end{tabular}

N/A = not available; to maintain Health Insurance Portability and Accountability Act compliance, all queries that return a value between one and 10 patients has a "null" output. In these instances, the incidence of the complication was determined as less than or equal to the maximum possible value (10 per cohort size)

90 days $(\mathrm{p}<0.01)$. Factor Xa inhibitors $(0.9 \%)$ had the lowest incidence of PE followed by enoxaparin $(1.1 \%)$, aspirin (1.2\%), and warfarin $(1.6 \%)$.

At 90 days, aspirin had the lowest incidence of postoperative anemia and transfusion but no differences in bleeding-related complications compared with the other agents. There was a difference in the incidence of postoperative anemia among the agents at all intervals $(\mathrm{p}<$ 0.01) (Table 4). The incidence of postoperative anemia remained the same from 2 weeks until 90 days postoperatively for aspirin (7\%) and factor Xa inhibitors (23\%). There were slight increases from 2 weeks to 90 days for warfarin (21\% to $22 \%)$ and enoxaparin (22\% to $23 \%)$. There was a difference in the incidence of a blood 
transfusion at all times $(\mathrm{p}<0.01)$ (Table 4). By 90 days, aspirin $(7 \%)$ had the lowest incidence of a blood transfusion followed by factor Xa inhibitors (9\%), warfarin (12\%), and enoxaparin (13\%). Given the HIPAA limitations of the database, we could not accurately find the incidence of bleeding-related complications (bleeding requiring surgical intervention, hemorrhage, hematoma, hemarthrosis) for aspirin until 90 days (Table 4). There was no difference in the incidence of bleeding-related complications at 90 days $(\mathrm{p}=0.81)$ for aspirin $(1.2 \%)$, factor Xa inhibitors $(1.4 \%)$, enoxaparin $(1.5 \%)$, or warfarin $(1.5 \%)$.

Factor Xa inhibitors had the highest rate of growth in utilization during our study period from 2007 to Quarter 4 of 2015. Factor Xa inhibitors had a compound annual growth rate of $43 \%$ followed by aspirin at $30 \%$ (Table 5). Enoxaparin utilization increased until 2011 when it peaked. The overall compound annual growth rate for enoxaparin was $3 \%$. Warfarin utilization has steady decrease with a compound annual growth rate of $-3 \%$.

\section{Discussion}

VTE remains a major potential complication after TKA, and its incidence has decreased in part owing to routine mechanical and chemical prophylaxis. There has been substantial debate regarding the preferred chemical prophylactic agent among aspirin, enoxaparin, warfarin, and factor Xa inhibitors when weighing VTE prophylaxis efficacy versus bleeding risk $[4,25,36]$. We sought to directly compare these four agents to examine VTE incidence, bleeding risk, and utilization patterns. When selected for the right patient, factor Xa inhibitors provided improved VTE prophylaxis compared with enoxaparin and warfarin, with a lower rate of blood transfusion. Aspirin provided comparable VTE prophylaxis compared with

Table 5. Utilization of each thromboprophylaxis agent

\begin{tabular}{lllll}
\hline Year & Aspirin & Enoxaparin & Warfarin & $\begin{array}{l}\text { Factor Xa } \\
\text { inhibitors }\end{array}$ \\
\hline 2007 & $47(5 \%)$ & $561(9 \%)$ & $671(11 \%)$ & $68(1 \%)$ \\
2008 & $82(8 \%)$ & $671(11 \%)$ & $725(12 \%)$ & $147(3 \%)$ \\
2009 & $98(10 \%)$ & $713(12 \%)$ & $754(12 \%)$ & $167(3 \%)$ \\
2010 & $99(10 \%)$ & $795(13 \%)$ & $760(13 \%)$ & $170(3 \%)$ \\
2011 & $37(4 \%)$ & $807(13 \%)$ & $785(13 \%)$ & $239(5 \%)$ \\
2012 & $33(3 \%)$ & $596(10 \%)$ & $679(11 \%)$ & $801(16 \%)$ \\
2013 & $64(6 \%)$ & $640(11 \%)$ & $644(11 \%)$ & $1077(21 \%)$ \\
2014 & $171(17 \%)$ & $624(10 \%)$ & $567(9 \%)$ & $1252(25 \%)$ \\
2015 & $385(38 \%)$ & $689(11 \%)$ & $511(8 \%)$ & $1159(23 \%)$ \\
CAGR & $30 \%$ & $3 \%$ & $-3 \%$ & $43 \%$ \\
\hline
\end{tabular}

CAGR = compound annual growth rate factor Xa inhibitors and improved VTE prophylaxis compared with enoxaparin and warfarin with the lowest risk of bleeding. Factor Xa inhibitors had the highest growth in utilization during our study period, followed by aspirin, when compared with enoxaparin and warfarin.

The first set of limitations of our study include those seen in other large database studies, as we do not have patient-specific identifiers, clinical observation, and assurance of accurately reported complications as found in randomized controlled trials or chart review studies. There is mixed evidence regarding the accuracy and validity of administrative claims $[8,11]$. This is particularly limiting in studying bleeding-related complications, as we used a collection of ICD-9 codes for hemorrhage, hematoma, hemarthrosis, and bleeding requiring surgical intervention, although bleeding secondary to anticoagulation may be reported in other ways we cannot capture (for example, increased bruising or venipuncture site bleeding), or not reported for billing purposes. Such bleeding outcomes would be better studied in randomized controlled trials, and as such, future study of these four agents in direct comparison is warranted. We also were unable to determine the dose and frequency of the agents we studied, which are important factors in determining their efficacy. In addition, we likely missed a large proportion of patients using aspirin for two reasons: (1) many who are prescribed aspirin may not need prescription billing because aspirin can be purchased over the counter, and (2) owing to our initial exclusion of all patients prescribed aspirin within 1 year before TKA to prevent confounding. Although we knew we would lose a portion of the cohort for only aspirin, this approach allowed us to specifically identify the cohort of patients who did have an aspirin prescription filled to ensure that was the sole prophylactic agent used after TKA. We were sufficiently powered to detect differences in DVT, PE, transfusion rate, postoperative anemia, and bleeding-related complications at 90 days, but did not have sufficient power to detect differences in PE and bleeding-related complications before 90 days.

Another set of limitations involves the creation of our study groups and change in practice patterns with time. Although we matched our patient cohorts by age and sex, there were still some differences in comorbidity profiles among the four groups, namely that of patients prescribed factor Xa being more medically complex and the only group with a median Charlson Comorbidity Index score of 2. In addition, the matching process uses a random sample from a larger group to select similar age and sex proportions. There may be differences in the larger cohort from which the sample was drawn in part because of prescribing patterns and baseline comorbidities (for example, warfarin being prescribed more frequently in older patients) and may not be perfectly representative of the general 
population. Another important limitation is that we were not able to control for all risk factors specific to VTE, which may have influenced selection of an anticoagulant. For example, patients who were at higher risk for VTE may have been appropriately prescribed enoxaparin, and the favorable aspirin outcomes may be attributable to patient selection. Moreover, as we excluded all preexisting codes for VTE, we likely missed the cohort of patients who were at the highest risk before baseline. Another important consideration is decreased transfusion rates with time in arthroplasty and increased adaptation of agents such as tranexamic acid, which have concurrently occurred as aspirin and factor Xa inhibitors are used more, and which may confound the results of the transfusion rate [6]. However, other studies have found low transfusion rates with aspirin as well $[33,34]$, thus we believe practice change is not the only explanation. Finally, it is reasonable to posit that certain patients, such as those receiving warfarin who may require international normalized ratio monitoring, may have had more attentive surveillance during the postoperative period, elevating the reported VTE and bleeding outcomes. Despite this, we identified lower VTE incidence with comparable bleeding risk with factor Xa inhibitors in the patients who were most medically complex.

Our findings regarding VTE prophylaxis do not have a direct correlate in the literature as other studies omit one or more of the two agents, but studies comparing multiple agents do help put our findings into context $[3,7,21,22,24,38,40,41]$. Aspirin has been found to have a low VTE rate, with no difference when compared with enoxaparin in a couple meta-analyses [3, 40]. These findings are similar to those in our study, although we found DVT incidence for aspirin to be lower than that of enoxaparin, which may be attributable in part to patient selection, as discussed above in the limitations. In comparison to warfarin, one retrospective review [21] of a large cohort of patients found aspirin to be as effective for VTE prophylaxis across patients with varying levels of risk, whereas another prospective study found aspirin to be inferior [22]. We found aspirin to have a stronger VTE prophylaxis profile, which may be attributable in part to its time-related correlation with early mobilization, healthier patients, and medication compliance. Data comparing aspirin and factor Xa inhibitors show mixed results, with randomized controlled trials showing no difference or an advantage to factor Xa inhibitors (rivaroxaban) for VTE prophylaxis [24, 41]. Similarly, we found that factor Xa inhibitors also had a lower VTE incidence than aspirin. Factor Xa inhibitors have been found to be more effective in preventing VTE compared with enoxaparin, as found in a recent meta-analysis of randomized controlled trials [38]. These findings correlate well with ours, as factor Xa inhibitors had a lower incidence of DVT and PE across all times. This effect may be attributable in part to the mechanism of action, but also ease of administration and compliance in comparison to enoxaparin [9, 39]. Data directly comparing factor Xa inhibitors with warfarin after TKA are limited, with a single randomized clinical trial finding no differences between the groups [7]. This contrasts with our study, in which factor Xa inhibitors showed better VTE prophylaxis when compared with warfarin. Possible explanations for this discrepancy include agent mechanism, compliance, and ease of monitoring. Given the above, our study does align with studies examining agents directly (through randomized clinical trials) or indirectly (through meta-analysis). Our study, however, provides a direct comparison of all four agents with the same methodology and as such we believe it contributes to the increasing knowledge of this important topic.

Bleeding risk often is cited as a disadvantage to the use of factor Xa inhibitors when compared with enoxaparin $[1,18,31]$. With the definitions and queries in our study, we found no difference in bleeding-related complications and a decreased transfusion rate compared with traditional anticoagulants. This possibly is explained by our grouping of factor Xa inhibitors. Two meta-analyses of high-quality trials showed an overall increased risk of bleeding with factor Xa inhibitors compared with enoxaparin, contrasting our study, however the factor Xa inhibitor used or the dose of the agent was found to play a role [30, 38]. In these studies, rivaroxaban was found to have an increased bleeding risk compared with enoxaparin, whereas apixaban had no difference in bleeding risk or even an improved profile. Low-dose factor Xa inhibitors also were found to have a lower bleeding risk. As we combined groups in our study, it is possible that the lack of increased bleeding may be attributable to the masking of higher-risk factor Xa inhibitors or selection of lower- risk, lower-dose factor Xa inhibitors. This warrants further investigation. Aspirin had the lowest bleeding risk overall in our study and parallels that seen in other studies when compared with factor Xa inhibitors [24, 41]. Studies on aspirin versus enoxaparin are mixed, with aspirin having a lower or equivalent rate of bleeding complications compared with enoxaparin [23, 40]. Although our study showed lower postoperative anemia and transfusion rates for aspirin when compared with warfarin, studies remains mixed regarding bleeding outcomes [21, 40].

Utilization trends for these agents are not well-studied. In one single-institution study, the rates of prescribing aspirin as the VTE agent increased after the convergence of the American Academy of Orthopaedic Surgeons and the American College of Chest Physicians guidelines, while all other agents including factor Xa inhibitors decreased [35]. In our study, the increase in factor Xa inhibitor use likely 
followed the results of the RECORD3 and RECORD4 trials. These trials showed superiority of factor Xa inhibitors compared with the previously highly used enoxaparin $[27,37]$. Further study is warranted on utilization trends, but we believe our results provide a new contribution as it captures prescribing trends during a time of changing practice guidelines.

Choice of thromboprophylaxis after primary TKA remains an important issue. Our study showed that aspirin is an effective thromboprophylactic agent with a favorable complication profile. Factor Xa inhibitors, even when used in patients who are more medically complex, also showed a low incidence of VTE. Enoxaparin, while showing a higher rate of bleeding complications, may still benefit patients who are appropriately selected. We believe our study is a springboard for two further questions: (1) How do we best decide which patients are appropriate for which class of VTE agents based on risk factors? (2) Of the factor Xa inhibitors, how do we decide between the lower bleedingrisk variants, such as apixaban, and aspirin? The Comparative Effectiveness of Pulmonary Embolism Prevention after Hip and Knee Replacement (PEPPER) trial, which has started to enroll patients, may help clarify this confusing topic [29].

\section{References}

1. Adam SS, McDuffie JR, Lachiewicz PF, Ortel TL, Williams JW Jr. Comparative effectiveness of new oral anticoagulants and standard thromboprophylaxis in patients having total hip or knee replacement: a systematic review. Ann Intern Med. 2013;159: 275-284.

2. American Academy Of Orthopaedic Surgeons. Preventing venous thromboembolic disease in patients undergoing elective hip and knee arthroplasty. Available at: http://www.aaos.org/research/ guidelines/VTE/VTE_full_guideline.pdf. Accessed May 13, 2017.

3. An VV, Phan K, Levy YD, Bruce WJ. Aspirin as thromboprophylaxis in hip and knee arthroplasty: a systematic review and meta-analysis. J Arthroplasty. 2016;31:2608-2616.

4. Anderson FA Jr, Huang W, Friedman RJ, Kwong LM, Lieberman JR, Pellegrini VD Jr; Orthopaedic Surgeon's Survey Stering Committee. Prevention of venous thromboembolism after hip or knee arthroplasty: findings from a 2008 survey of US orthopedic surgeons. J Arthroplasty. 2012;27:659-666.e5.

5. As-Sultany M, Pagkalos J, Yeganeh S, Craigs CL, Korres N, West RM, Tsiridis E. Use of oral direct factor Xa inhibiting anticoagulants in elective hip and knee arthroplasty: a metaanalysis of efficacy and safety profiles compared with those of low-molecular-weight heparins. Curr Vasc Pharmacol. 2013;11:366-375.

6. Bedard NA, Pugely AJ, Lux NR, Liu SS, Gao Y, Callaghan JJ. Recent trends in blood utilization after primary hip and knee arthroplasty. J Arthroplasty. 2017;32:724-727.

7. Bern MM, Hazel D, Deeran E, Richmond JR, Ward DM, Spitz DJ, Mattingly DA, Bono JV, Berezin RH, Hou L, Miley GB, Bierbaum BE. Low dose compared to variable dose Warfarin and to Fondaparinux as prophylaxis for thromboembolism after elective hip or knee replacement surgery: a randomized, prospective study. Thromb J. 2015;13:32.

8. Bozic KJ, Bashyal RK, Anthony SG, Chiu V, Shulman B, Rubash HE. Is administratively coded comorbidity and complication data in total joint arthroplasty valid? Clin Orthop Relat Res. 2013;471: 201-205.

9. Carrothers AD, Rodriguez-Elizalde SR, Rogers BA, Razmjou H, Gollish JD, Murnaghan JJ. Patient-reported compliance with thromboprophylaxis using an oral factor Xa inhibitor (rivaroxaban) following total hip and total knee arthroplasty. $J$ Arthroplasty. 2014;29:1463-1467.

10. Cho SE, Delate T, Witt DM, Clark NP. Thromboembolic and bleeding outcomes of extended duration low-intensity warfarin following elective total knee arthroplasty. Thromb Res. 2015;135: 267-271.

11. Clair AJ, Inneh IA, Iorio R, Berend KR, Della Valle CJ, Healy WL, Pelligrini VD. Can administrative data be used to analyze complications following total joint arthroplasty? J Arthroplasty. 2015;30(9 suppl):17-20.

12. Elixhauser A, Steiner C, Harris DR, Coffey RM. Comorbidity measures for use with administrative data. Med Care. 1998;36:827.

13. Falck-Ytter Y, Francis CW, Johanson NA, Curley C, Dahl OE, Schulman S, Ortel TL, Pauker SG, Colwell Jr CW. Prevention of VTE in orthopedic surgery patients: antithrombotic therapy and prevention of thrombosis, 9th ed: American College of Chest Physicians Evidence-Based Clinical Practice Guidelines. Chest. 2012;141(2 suppl):e278S-e325S.

14. Farfan M, Bautista M, Bonilla G, Rojas J, Llinas A, Navas J. Worldwide adherence to ACCP guidelines for thromboprophylaxis after major orthopedic surgery: a systematic review of the literature and meta-analysis. Thromb Res. 2016;141:163-170.

15. Feng W, Wu K, Liu Z, Kong G, Deng Z, Chen S, Wu Y, Chen M, Liu S, Wang H. Oral direct factor Xa inhibitor versus enoxaparin for thromboprophylaxis after hip or knee arthroplasty: systemic review, traditional meta-analysis, dose-response meta-analysis and network meta-analysis. Thromb Res. 2015;136:1133-1144.

16. Fuji T, Wang CJ, Fujita S, Kawai Y, Nakamura M, Kimura T, Ibusuki K, Ushida H, Abe K, Tachibana S. Safety and efficacy of edoxaban, an oral factor Xa inhibitor, versus enoxaparin for thromboprophylaxis after total knee arthroplasty: the STARS E-3 trial. Thromb Res. 2014;134:1198-1204.

17. Geerts WH, Bergqvist D, Pineo GF, Heit JA, Samama CM, Lassen MR, Colwell CW; American College of Chest Physicians. Prevention of venous thromboembolism: American College of Chest Physicians Evidence-Based Clinical Practice Guidelines (8th Edition). Chest. 2008;133(6 suppl):381S-453S.

18. Gomez-Outes A, Terleira-Fernandez AI, Suarez-Gea ML, Vargas-Castrillon E. Dabigatran, rivaroxaban, or apixaban versus enoxaparin for thromboprophylaxis after total hip or knee replacement: systematic review, meta-analysis, and indirect treatment comparisons. BMJ. 2012;344:e3675.

19. Gordon M, Stark A, Skoldenberg OG, Karrholm J, Garellick G. The influence of comorbidity scores on re-operations following primary total hip replacement: comparison and validation of three comorbidity measures. Bone Joint J. 2013;95:1184-1191.

20. Healy WL, Della Valle CJ, Iorio R, Berend KR, Cushner FD, Dalury DF, Lonner JH. Complications of total knee arthroplasty: standardized list and definitions of the Knee Society. Clin Orthop Relat Res. 2013;471:215-220.

21. Huang RC, Parvizi J, Hozack WJ, Chen AF, Austin MS. Aspirin is as effective as and safer than warfarin for patients at higher risk of venous thromboembolism undergoing total joint arthroplasty. $J$ Arthroplasty. 2016;31(9 suppl):83-86.

22. Intermountain Joint Replacement Center Writing Committee. A prospective comparison of warfarin to aspirin for 
thromboprophylaxis in total hip and total knee arthroplasty. $J$ Arthroplasty. 2012;27:1-9.e2.

23. Jameson SS, Baker PN, Charman SC, Deehan DJ, Reed MR, Gregg PJ, Van der Meulen JH. The effect of aspirin and lowmolecular-weight heparin on venous thromboembolism after knee replacement: a non-randomised comparison using National Joint Registry Data. J Bone Joint Surg Br. 2012;94:914-918.

24. Jiang Y, Du H, Liu J, Zhou Y. Aspirin combined with mechanical measures to prevent venous thromboembolism after total knee arthroplasty: a randomized controlled trial. Chin Med J (Engl). 2014; 127:2201-2205.

25. Knesek D, Peterson TC, Markel DC. Thromboembolic prophylaxis in total joint arthroplasty. Thrombosis. 2012;2012:837896.

26. Lachiewicz PF. Comparison of ACCP and AAOS guidelines for VTE prophylaxis after total hip and total knee arthroplasty. Orthopedics. 2009;32:74-78.

27. Lassen MR, Ageno W, Borris LC, Lieberman JR, Rosencher N, Bandel TJ, Misselwitz F, Turpie AG; RECORD3 Investigators. Rivaroxaban versus enoxaparin for thromboprophylaxis after total knee arthroplasty. N Engl J Med. 2008;358:2776-2786.

28. Lieberman JR, Pensak MJ. Prevention of venous thromboembolic disease after total hip and knee arthroplasty. J Bone Joint Surg Am. 2013;95:1801-1811.

29. National Institutes of Health. ClinicalTrials.gov. Comparative Effectiveness of Pulmonary Embolism Prevention After Hip and Knee Replacement (PEPPER). Available at: https://clinicaltrials. gov/ct2/show/NCT02810704. Accessed May 11, 2017.

30. Neumann I, Rada G, Claro J, Carrasco-Labra A, Thorlund K, Akl EA, Bates SM, Guyatt GH. Oral direct Factor xa inhibitors versus low-molecular-weight heparin to prevent venous thromboembolism in patients undergoing total hip or knee replacement: a systematic review and meta-analysis. Ann Intern Med. 2012;156:710-719.

31. Ning GZ, Kan SL, Chen LX, Shangguan L, Feng SQ, Zhou Y. Rivaroxaban for thromboprophylaxis after total hip or knee arthroplasty: a meta-analysis with trial sequential analysis of randomized controlled trials. Sci Rep. 2016;6:23726.

32. Pierce TP, Elmallah RK, Jauregui JJ, Cherian JJ, Mont MA. What's new in venous thromboembolic prophylaxis following total knee and total hip arthroplasty? An update. Surg Technol Int. 2015;26:234-237.

33. Radzak KN, Wages JJ, Hall KE, Nakasone CK. Rate of transfusions after total knee arthroplasty in patients receiving Lovenox or high-dose aspirin. J Arthroplasty. 2016;31:2447-2451.

34. Schwab PE, Lavand'homme P, Yombi J, Thienpont E. Aspirin mono-therapy continuation does not result in more bleeding after knee arthroplasty. Knee Surg Sports Traumatol Arthrosc. 2015 Oct 29. [Epub ahead of print].

35. Shah SS, Satin AM, Mullen JR, Merwin S, Goldin M, Sgaglione NA. Impact of recent guideline changes on aspirin prescribing after knee arthroplasty. J Orthop Surg Res. 2016;11:123.

36. Stewart DW, Freshour JE. Aspirin for the prophylaxis of venous thromboembolic events in orthopedic surgery patients: a comparison of the AAOS and ACCP guidelines with review of the evidence. Ann Pharmacother. 2013;47:63-74.

37. Turpie AG, Lassen MR, Davidson BL, Bauer KA, Gent M, Kwong LM, Cushner FD, Lotke PA, Berkowitz SD, Bandel TJ, Benson A, Misselwitz F, Fisher WD; RECORD4 Investigators. Rivaroxaban versus enoxaparin for thromboprophylaxis after total knee arthroplasty (RECORD4): a randomised trial. Lancet. 2009;373:1673-1680.

38. Venker BT, Ganti BR, Lin H, Lee ED, Nunley RM, Gage BF. Safety and efficacy of new anticoagulants for the prevention of venous thromboembolism after hip and knee arthroplasty: a metaanalysis. J Arthroplasty. 2017;32:645-652.

39. Wilke T, Moock J, Müller S, Pfannkuche M, Kurth A. Nonadherence in outpatient thrombosis prophylaxis with low molecular weight heparins after major orthopaedic surgery. Clin Orthop Relat Res. 2010;468:2437-2453.

40. Wilson DG, Poole WE, Chauhan SK, Rogers BA. Systematic review of aspirin for thromboprophylaxis in modern elective total hip and knee arthroplasty. Bone Joint J. 2016;98:1056-1061.

41. Zou Y, Tian S, Wang Y, Sun K. Administering aspirin, rivaroxaban and low-molecular-weight heparin to prevent deep venous thrombosis after total knee arthroplasty. Blood Coagul Fibrinolysis. 2014;25:660-664. 